\title{
Identificação por Radiofreqüência: Aplicações e Vulnerabilidades da Tecnologia RFID
}

\author{
Professor Especialista José Maurício dos Santos Pinheiro (Seqüencial de Redes de \\ Computadores - UniFOA) - jm.pinheiro@ projetoderedes.com.br
}

\begin{abstract}
Resumo
Uma das novidades tecnológicas mais controvertidas no momento é a tecnologia RFID, acrônimo de Identificação por Rádio Freqüência (Radio Frequency Identification), que representa uma evolução em termos de tecnologia para computação embarcada e que vem sendo cada vez mais utilizada em conjunto com outras tecnologias de identificação automática e as redes de computadores nos setores onde há necessidade de rastreamento $e$ coleta de dados, como transportes e logística, indústria, comércio e segurança. Apesar das grandes vantagens apresentadas, tal tecnologia pode trazer também grandes problemas aos seus usuários dependendo da forma como é aplicada. Este artigo tem como objetivo apresentar um breve histórico do desenvolvimento e funcionamento da tecnologia RFID, abordando com maior profundidade suas aplicações, vantagens e fragilidades, bem como as alternativas para contornar os problemas decorrentes de sua aplicação.
\end{abstract}

Palavras-chave: Identificação; Radiofreqüência; Aplicação; Vulnerabilidade; Segurança.

\section{Origens da tecnologia}

A tecnologia RFID tem suas origens nos sistemas de radares utilizados na Segunda Guerra Mundial. Os militares utilizavam radares para avisá-los com antecedência sobre os aviões que se aproximavam enquanto eles ainda estavam bem distantes. $\mathrm{O}$ grande problema era identificar dentre esses aviões qual era o inimigo e qual era o aliado.

Os alemães descobriram que, se os pilotos girassem seus aviões quando estivessem retornando à base, iriam modificar o sinal de radio que seria refletido de volta ao radar. Esse método simples alertava os técnicos responsáveis pelo radar quando se tratava de aviões alemães ou não. Essa técnica foi considerada o primeiro sistema passivo de identificação automática por radiofrequiência.

Posteriormente, os ingleses desenvolveram o primeiro identificador ativo batizado como IFF (Identify Friend or Foe). Foram instalados transmissores nos aviões britânicos e quando esses transmissores recebiam sinais das estações de radar no solo, começavam a transmitir um sinal de resposta que identificava o aparelho como Friend (amigo), caso contrário, ele seria Foe (inimigo).

Os modernos dispositivos de identificação por radiofreqüência funcionam baseados no mesmo principio básico do sistema IFF. Em 1999, o Massachusetts Institute of Technology (MIT) e outros centros de pesquisa no mundo iniciaram o estudo de uma arquitetura de identificação automática que utilizava os recursos da transmissão por radiofreqüência para servir como modelo no desenvolvimento de novas aplicações de rastreamento e localização de produtos. Nesta nova arquitetura, um sinal de radiofreqüência é enviado por um dispositivo leitor que possui uma antena, a um microchip, o qual é ativado pelo sinal de radiofrequiência, refletindo de volta o sinal enviado (sistemas passivos) ou transmitindo seu próprio sinal 
(sistemas ativos). Este dispositivo leitor também pode gravar novos dados no microchip, no caso de um sistema de leitura/escrita (Figura 1).

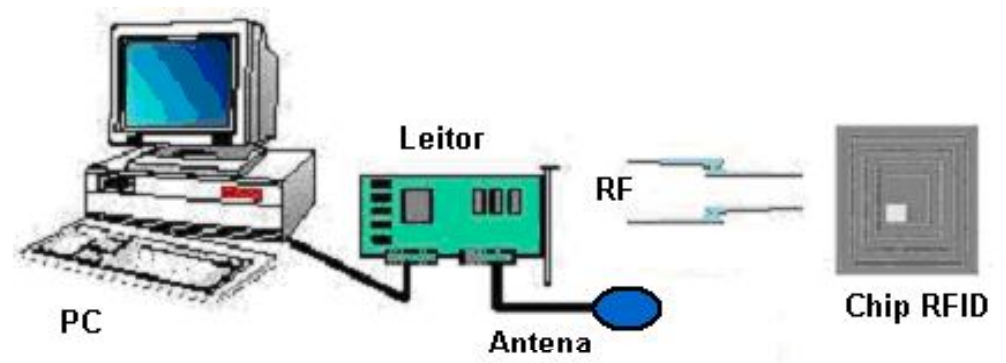

Figura 1 - Exemplo de comunicação entre dispositivo leitor e o microchip

\subsection{Identificação automática}

"Identificação automática" é um termo generalizado para as tecnologias que permitem que dispositivos leitores identifiquem objetos automaticamente. A RFID é um tipo de tecnologia de identificação automática, uma vez que objetos podem ser etiquetados e identificados de forma estruturada. Utilizando ondas de rádio, um dispositivo de leitura capta automaticamente os dados contidos no microchip, permitindo que estes sejam, então, processados.

Dessa forma, um microchip pode fornecer automaticamente informações sobre um produto, tais como localização física, código do fabricante, fornecedor, comprador, etc. Também é possível ajustar a informação fornecida de acordo com regras estabelecidas nos servidores que intercambiam os dados com os leitores e microchip.

\section{Entendendo a tecnologia}

Como o próprio nome sugere, a identificação por radiofreqüência é uma tecnologia de identificação automática que utiliza ondas eletromagnéticas como meio para capturar as informações contidas em um dispositivo eletrônico conhecido como "etiqueta RFID".

Esta etiqueta, também chamada de microchip, Transponder (transmissor + receptor), RF Tag, ou simplesmente Tag, responde aos sinais de radiofrequiência de um Leitor, enviando de volta informações quanto a sua localização e identificação, através de um chip, um circuito eletrônico e uma antena interna (Figura 2).

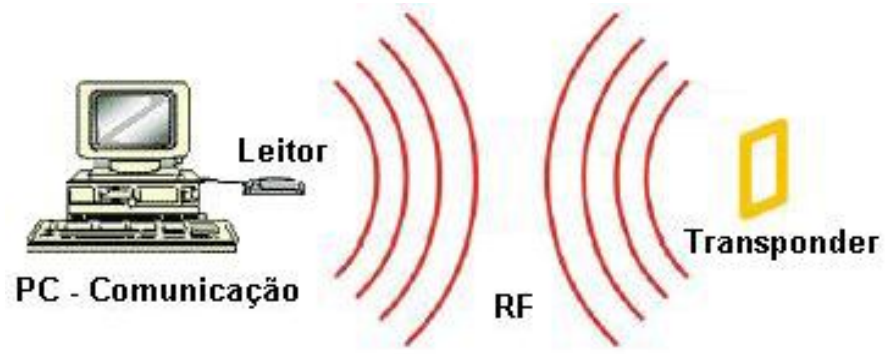

Figura 2 - Exemplo de comunicação entre Leitor e Transponder RFID

Um Transponder pode ser dividido em três partes básicas: um substrato, onde encontramos o chip e outros componentes eletrônicos, a antena, que é conectada ao chip e o encapsulamento, normalmente em PVC, Epóxi, Resina, etc (Figura 3). 
O principal componente do Transponder é o chip que, além de realizar o controle e a comunicação com o Leitor, possui a memória onde são armazenados os dados.

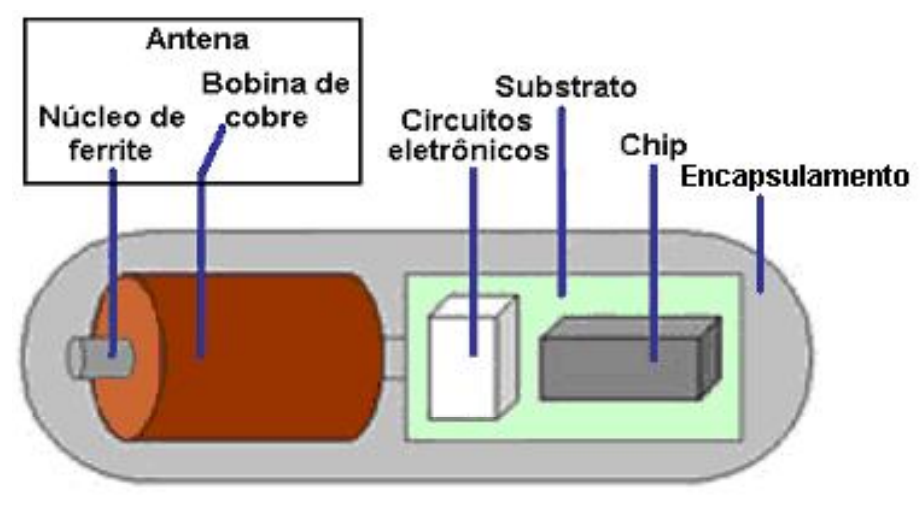

Figura 3 - Estrutura típica de um Transponder

Existem Transponders do tipo somente leitura (Read Only), que possuem um código pré-gravado de fábrica em sua memória e Transponders do tipo leitura/escrita (Read/Write), onde é possível ler e gravar dados na memória.

O Leitor RFID opera pela emissão de um sinal de radiofreqüência (a fonte de energia que alimenta o chip do Transponder), que por sua vez, responde com o conteúdo de sua memória. Ao contrário de um leitor para código de barras, um leitor RFID não necessita de contato visual com a etiqueta para ler os dados e a leitura pode ser feita através de diversos materiais como plástico, madeira, vidro, papel, tecido, entre outros. $\mathrm{O}$ dispositivo pode realizar ainda a leitura simultânea de milhares de microchips e armazenar o resultado em uma memória para posterior envio ao servidor do sistema.

A distância de leitura entre Leitor e Transponder é um fator muito importante para o bom funcionamento do sistema RFID. Essa distância depende de diversos fatores tais como: tipo do Transponder (se ativo ou passivo), tamanho da antena, potência do Leitor, frequiência empregada, dentre outros, devendo ser otimizada para cada aplicação e com o alcance variando de poucos centímetros a centenas de metros.

O Transponder pode ser alimentado indutivamente pelos sinais de rádio que são emitidos pelo Leitor RFID tanto para leitura quanto escrita (microchip passivo) ou pode possuir sua própria fonte de energia, por exemplo, uma pequena bateria (microchip ativo). Quando ativado pelo Leitor, o chip decodifica a solicitação contida no sinal de rádio e gera um sinal de resposta usando a própria energia da radiofreqüência recebida.

A capacidade de armazenamento de um microchip RFID é limitada, variando conforme o tipo de chip. Normalmente, em sistemas passivos, as capacidades variam entre 64bits e 8 kilobits. As etiquetas RFID mais novas podem armazenar, em média, de 114 bytes a 1Kbyte de informação na memória, dependendo de sua aplicação. 


\section{Vantagens e pontos positivos da tecnologia}

Sem dúvida alguma a tecnologia RFID oferece inúmeras possibilidades de aplicação, apresentando soluções para os sistemas de rastreamento e identificação com diversas vantagens:

Maior confiabilidade;

Aumento da segurança em operações repetitivas;

Redução de custos operacionais;

Eliminação de erros humanos;

Aumento na velocidade dos processos, devido à automação dos mesmos;

Melhor controle de qualidade com conseqüente redução de perdas;

Operação sem a necessidade de contato físico ou permanência em ambientes insalubres (lugares úmidos, corrosivos, com extremos de temperaturas muito altas ou muito baixas), locais sujeitos à vibração, choques, etc.

A confiabilidade é uma das maiores vantagens da tecnologia RFID. Ao contrário da maioria dos sistemas existentes no mercado, em nenhuma situação a operação de leitura dos Transponders depende de contato físico ou elétrico. Ficam assim eliminados os problemas decorrentes de oxidação, sujeira e desgaste de superfícies. A operação é simples, bastando aproximar o Leitor do Transponder, não sendo necessária uma posição predefinida para a leitura.

A tecnologia RFID apresenta ainda como pontos positivos:

Capacidade de armazenamento dos dados coletados;

Leitura simultânea de milhares de itens diferentes por segundo;

Captura dos dados sem necessidade de visada direta;

Possibilidade de reutilização e alta durabilidade das etiquetas;

Rastreabilidade de produtos e de seres vivos.

\section{Aplicações da tecnologia RFID}

Os apelos da tecnologia RFID são instigantes. As etiquetas com microchip colocadas nos produtos funcionam como uma espécie de documento de identificação com informações de preço, prazo de validade, número do lote, entre outras, além de permitir uma relação mais afinada entre linhas de produção, os consumidores e os sistemas de informação de uma organização.

A tecnologia RFID é usada em todas as áreas que necessitam da captura automática de dados, permitindo a identificação de objetos sem contato físico, via radiofreqüência, com aplicações que variam de sistemas de pagamento via Internet, seguros, a automatização industrial e o controle de acesso (FINKENZELLER, 2003).

De acordo com Pinheiro (2004):

É cada vez mais intensa a aplicação das novas tecnologias sem fio na sociedade atual, fato que tem provocado muitas mudanças nos hábitos e no comportamento das pessoas. O simples hábito de fazer compras ou mesmo pagar uma tarifa de pedágio com um cartão de crédito, entregando esse cartão para que seja passado por uma leitora magnética, pode estar chegando ao fim. 
Considere também o seu uso em seres vivos. Já existem microchips para uso em pessoas e animais, que ficam debaixo da pele e que podem ser rastreados até mesmo a centenas de metros de distância.

Dentre as variadas aplicações para etiquetas RFID podemos destacar:

\subsection{Pedágios}

A tecnologia já se tornou comum nos pedágios de algumas rodovias. Ao invés de os carros pararem, um cartão provido com o microchip RFID é colocado no pára-brisa do veículo, enviando seu código de identificação para as antenas ou leitores eletrônicos localizados na cabine de cobrança (Figura 4). Uma vez reconhecido o código, a passagem é liberada.

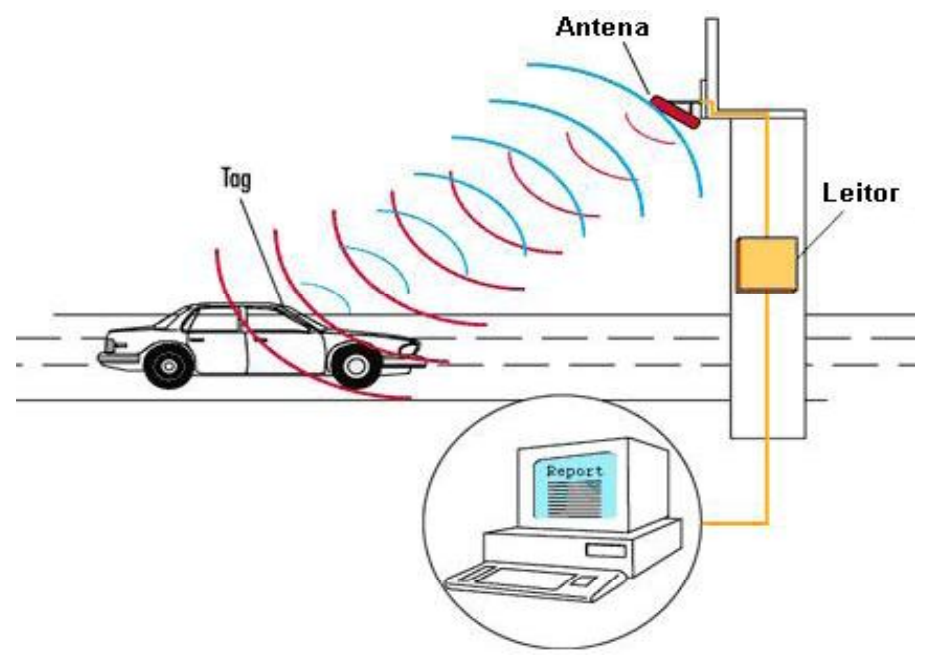

Figura 4 - Aplicação de RFID em postos de pedágio

\subsection{Aplicações médicas}

Usados embaixo da pele, os dispositivos podem armazenar registros completos que incluem desde a identidade, o tipo sangüíneo e outros detalhes da condição do paciente a fim de agilizar o seu tratamento. No caso de uma emergência, o chip pode salvar vidas, já que reduz a necessidade de testes de grupo sangüíneo, alergias ou doenças crônicas, além de fornecer o histórico atualizado dos medicamentos em uso pelo paciente. Com isso obtém-se maior agilidade na busca de informações e tratamento sem a necessidade de localização dos prontuários médicos.

O uniforme dos funcionários, crachás de visitantes, remédios e equipamentos também podem ser etiquetados, criando um ambiente de administração estruturado, reduzindo erros e aumentando a segurança das pessoas.

\subsection{Controle de acesso}

Implantes de chips RFID no corpo humano também podem ser usados como uma alternativa para identificar fraudes, prover a segurança no acesso a lugares restritos como salas de controle, cofres de bancos, Datacenters, entre outros. Combinado com outros 
sensores para monitorar as funções do corpo, o dispositivo poderia armazenar as condições psicológicas das pessoas e detectar condições de stress e medo, por exemplo. Atualmente prisões de algumas cidades norte-americanas utilizam pulseiras metálicas com Transponders para identificar e localizar prisioneiros dentro dos estabelecimentos penais.

Outra aplicação para controle de acesso está nos ingressos para eventos como cinemas, teatros, estádios de futebol, etc. Ao chegar ao local, a pessoa passa o ingresso (com um Transponder) por um leitor instalado na entrada, liberando o acesso aos seus assentos e áreas de alimentação. Nesse caso, o uso de dispositivos RFID também dificulta a falsificação dos ingressos e pode aumentar a rapidez e a segurança do acesso das pessoas a esses locais (Figura 5).

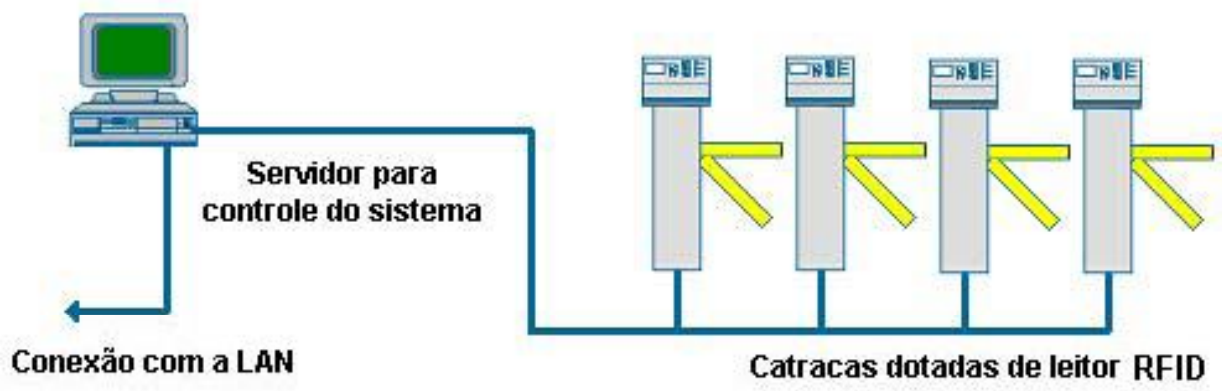

Figura 5 - Tecnologia RFID empregada no controle de acesso

\subsection{Proteção pessoal}

Microchips RFID estão sendo desenvolvidos para uso acoplados a dispositivos do tipo GPS (Global Positioning System), sistemas baseados em satélites e desenvolvidos para navegação, que permitem localizar, com precisão, a posição de um produto ou pessoa em qualquer ponto da superfície da terra. Utilizados dessa forma, poderiam ser usados em pessoas (executivos, por exemplo), como uma forma de proteção e localização no caso de atentados ou seqüestros.

\subsection{Transportes aéreos, terrestres e marítimos}

Algumas empresas aéreas estão utilizando as etiquetas RFID nas malas dos passageiros, procurando dessa forma reduzir perdas de bagagens e facilitar o itinerário das malas nos casos de mudanças nos planos de vôo das companhias. Da mesma forma, os portos também podem utilizar a tecnologia RFID para rastrear bagagens de passageiros, containeres e demais cargas transportadas em navios.

Outra aplicação é o uso de Transponders em cargas terrestres para circulação em rodovias, visando um melhor controle dos produtos e fiscalização na emissão de notas fiscais com o intuito de reduzir contrabando e até mesmo o tráfico de drogas.

\subsection{Logística}

A logística é um setor que vem se expandindo devido a constantes mudanças no mercado mundial. Com o avanço da tecnologia, estão se desenvolvendo novos recursos e oportunidades para as empresas realizarem seus negócios. 
Dentro da logística estão envolvidos vários processos, como transporte, estoque, armazenagem, manuseio de materiais entre outros e a utilização da tecnologia RFID se faz presente visando redução de custos, menor desperdício, maior agilidade nos processos e maior satisfação dos clientes. Dentre as aplicações da RFID neste setor destacam-se:

Auxílio nas operações de recebimento, separação, transporte, armazenamento e expedição de materiais em depósitos e armazéns;

Inventário de produtos em tempo real, garantindo um correto levantamento dos estoques existentes;

Controle de qualidade, possibilitando o controle de produtos de forma integrada e automática ao sistema de manufatura.

\subsection{Linhas de montagem industriais}

Uma aplicação bastante promissora para a tecnologia RFID está nas linhas de montagens de veículos ou de máquinas industriais. Nesse tipo de indústria, normalmente os produtos se movimentam com velocidade constante e não podem reduzir a marcha para leitura. Com a RFID todo o processo de montagem pode ser monitorado desde o início até a entrega final do produto ao consumidor, facilitando, inclusive, o acompanhamento nos casos de manutenção (Figura 6).

No caso dos veículos, a tecnologia pode ser utilizada ainda como integrante de sistemas de proteção contra furtos, atuando no sistema de ignição até o travamento de portas e bloqueio de combustível do veículo.

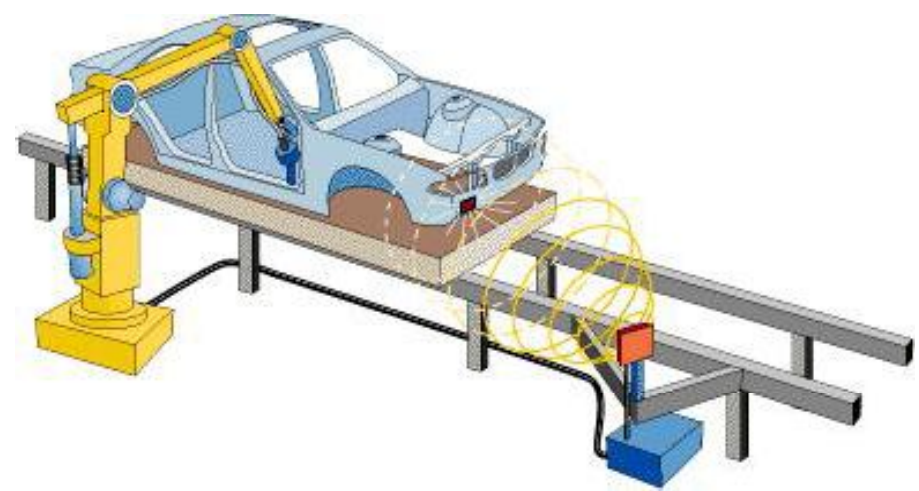

Figura 6 - RFID em linha de montagem de veículos

\subsection{Aplicações financeiras}

Podemos encontrar aplicações da tecnologia RFID especialmente relacionadas à segurança nas transações bancárias. Uma aplicação está nos cartões bancários do tipo "Smart Card".

Entende-se como Smart Card todo dispositivo que permite um processamento interno, cálculos aritméticos e a tomada de decisões a partir de determinadas informações codificadas. Iniciativas recentes incluem a combinação de cartões bancários deste tipo com Transponders (Figura 7). Por exemplo, quando um cliente portando um Smart Card, associado com o Transponder RFID, chega a um caixa eletrônico bastará fornecer sua senha de acesso e um 
Leitor, junto ao equipamento, varrerá seu corpo buscando captar as informações contidas no chip, que transmitirá outros dados pessoais e autorizará a transação.

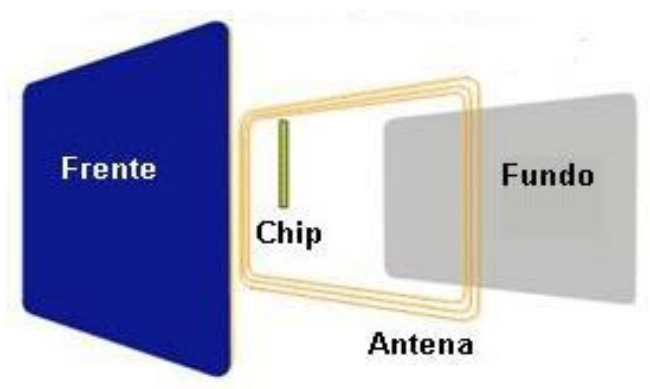

Figura 7 - Exemplo de um Transponder inserido em Smart Card

Uma outra aplicação possível seria colocar Transponders no papel moeda, procurando com isso reduzir a falsificação. Com o chip nas cédulas de dinheiro, a contagem de grandes quantias também seria feita muito mais rapidamente.

\subsection{Aplicações biométricas}

A União Européia pretende adotar o uso de passaportes biométricos dotados de um microchip RFID que, além da identificação do portador (nome, filiação, data e país de nascimento e outras informações) conterá sua foto digitalizada e dados de identificação com parâmetros característicos do rosto humano (distâncias e ângulos entre olhos, boca, nariz, maçãs faciais) e, no futuro, a impressão digital digitalizada.

O governo dos EUA também está adotando o uso de um passaporte com dados biométricos capazes de serem lidos por leitores especiais. O objetivo é dificultar a falsificação do documento e facilitar a tarefa das autoridades de imigração ao rastrear um indivíduo (ou, pelo menos, seu passaporte) em qualquer região onde se implemente uma rede de sensores. Neste caso, em se tratando de um chip RFID, os sinais podem ser captados por sensores situados no raio de alguns metros dentro de locais de grande movimento como aeroportos, estação ferroviária, rodoviária, etc.

\section{Questões de padronização}

Uma questão importante que envolve a tecnologia diz respeito à padronização das frequiências utilizadas pelas etiquetas, isto é, a definição de uma "linguagem universal" para que os produtos possam ler lidos por toda a indústria, de maneira uniforme.

O fato é que os investimentos nas etiquetas RFID não se limitam ao microchip anexado ao produto. Por trás das etiquetas estão antenas que capturam dados e os transmitem para leitoras, passando em seguida para um sistema de filtragem de informações que, finalmente, precisa se comunicar com diferentes bases de dados.

O MIT e outros centros de pesquisa têm se dedicado ao estudo de um padrão que utilize os recursos da tecnologia de radiofreqüência e sirva de referência para o desenvolvimento de novos dispositivos de armazenamento de dados. Foi desse estudo, inclusive, que nasceu o Código Eletrônico de Produtos (Electronic Product Code - EPC), usado atualmente em muitos países. 


\section{RFID e o Código de Barras}

A primeira tecnologia desenvolvida com o objetivo de solucionar problemas de rastreamento e identificação de produtos foi o código de barras. Nesses sistemas, dispositivos leitores (canetas ópticas, pistolas laser e outros), transformam as informações contidas em uma etiqueta com um código de barras impresso, em seqüências de sinais elétricos correspondentes e proporcionais aos dados nela contidos, enviando essa informação para um terminal que armazena os dados coletados e, posteriormente, os transfere para processamento (Figura 8).

A tecnologia RFID pode ser utilizada na identificação e rastreamento de produtos em situações onde o código de barras ou outra tecnologia de identificação não atenda a todas as necessidades, podendo ser usada isoladamente ou em conjunto com esses outros métodos de identificação. Entretanto, a tecnologia não deve ser considerada como um substituto dos métodos de identificação existentes atualmente. Ao contrário, essas tecnologias devem coexistir por muito tempo, aplicando-se uma ou outra à situação mais conveniente.

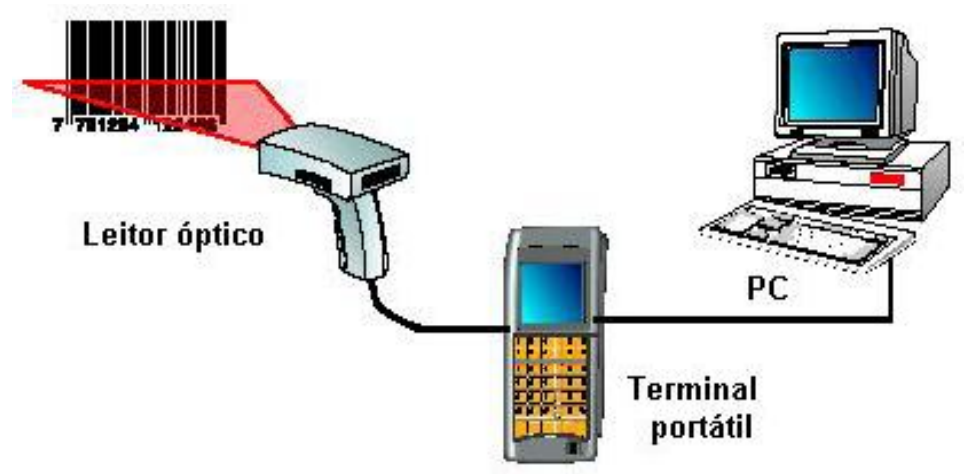

Figura 8 - Exemplo de aplicação do leitor de código de barras

O código de barras ainda é uma boa solução quando o objetivo é coletar informações em processos bem estruturados e projetados, onde se tem acesso direto ao produto, como armazéns, por exemplo. Já as etiquetas RFID são mais eficientes na coleta de informações de recursos móveis (sem visada direta) e de processos de negócios não estruturados, oferecendo a esses ambientes um controle mais eficiente e sistemático.

\section{Problemas com a tecnologia}

A tecnologia RFID tem como característica básica armazenar dados e facilitar o rastreamento onde está localizado o Transponder. Portanto, a implantação desta tecnologia sem um tratamento cuidadoso dos aspectos de segurança pode acarretar em graves transtornos aos seus usuários.

Alguns dos problemas que possivelmente trarão mais complicações às pessoas e organizações caso a tecnologia RFID seja implantada em larga escala e sem existir o devido cuidado com a segurança são os seguintes:

Violação de integridade: uma etiqueta possui dados específicos do material ou pessoa em que está localizada. Se esta for retirada e colocada em outro local poderá causar sérios prejuízos ao seu proprietário. Exemplo: A troca da etiqueta de um produto por outro poderá lesar o estabelecimento comercial ou o cliente; 
Cópia de etiquetas: uma pessoa mal intencionada e com conhecimento técnico poderia copiar os dados de uma etiqueta (usando um leitor) e criar uma nova etiqueta (um clone) com os mesmos dados. Exemplo: automóveis com dispositivos RFID que não necessitam da chave podem ter seu código copiado, facilitando seu roubo;

Monitoramento da etiqueta: obtenção de dados para uso indevido sem envolver fisicamente a etiqueta. Exemplo: as informações bancárias ou pessoais de um indivíduo podem ser rastreadas e usadas indevidamente por terceiros.

\section{Vulnerabilidades da tecnologia}

Atualmente, a maioria das aplicações da tecnologia RFID está voltada para a segurança pessoal e patrimonial. Para uma análise mais detalhada das vulnerabilidades mais aparentes nestas aplicações, alguns dos exemplos citados anteriormente podem ser utilizados:

\subsection{Transporte de bens}

Vários portos e aeroportos pelo mundo já estão usando RFID para controlar a movimentação de bagagens dos seus usuários. Porém, esse tipo de aplicação da tecnologia pode representar um grande problema se a etiqueta, integrada ao objeto transportado, armazenar uma quantidade muito grande de informações.

Por exemplo, uma etiqueta clonada ou falsificada, tem seu conteúdo modificado e passa a transportar, juntamente com os dados válidos, um vírus. Quando for lida, poderá causar um estouro de memória, infectando o sistema leitor e o servidor com esse vírus. Uma vez alojado no servidor, o vírus poderia infectar todo o banco de dados e corromper outras etiquetas cadastradas ou ainda, instalar "backdoors" (pequenos programas que permitem o envio de informações pela internet) e desviar informações sigilosas para uso indevido por outras pessoas.

Devido ao custo ainda elevado da tecnologia, seria praticamente impossível se proteger contra tais ataques, pois seriam necessários protocolos mais complexos que os atuais para controlar o acesso dos leitores às informações contidas no microchip. Mesmo as etiquetas passivas, que tem um raio de ação de poucos metros, podem sofrer interceptação e extravio de suas informações. Pensando em etiquetas ativas, o problema torna-se bem mais crítico.

\subsection{Segurança pessoal e material}

No caso da segurança pessoal com monitoração via satélite, deve-se considerar que RFID e GPS são tecnologias distintas. Para que uma pessoa, usando um microchip RFID, possa ser detectada por um satélite é necessário que ela porte um dispositivo transmissor GPS, que ainda é relativamente grande e necessita de uma bateria de longa duração para funcionar, associado ao microchip, que contém suas informações pessoais. Somente dessa forma sistemas RFID com chips implantados em pessoas permitem a rastreabilidade a longas distâncias para prover segurança pessoal.

No caso dos bens materiais, argumenta-se que distância de leitura de uma etiqueta RFID pode variar quando há obstáculos entre o leitor e o emissor, por exemplo, os móveis com etiquetas RFID contidos no interior de uma residência. 
Assim, para que pessoas mal intencionadas possam utilizar essa tecnologia para praticar suas ações ilícitas, elas teriam que possuir um receptor muito mais sensível do que o normal. Mas isso não é um grande problema atualmente. Apesar de ser necessário dispender um valor maior em recursos para se adquirir ou mesmo construir um dispositivo desse tipo, é perfeitamente possível tal ação.

Uma prova dessa afirmação é que, apesar de ser considerado extremamente seguro e até infalível, o sistema de segurança que utiliza a tecnologia RFID em chaves de automóveis teve uma falha descoberta. Tais sistemas se baseiam em transmissores passivos (sem necessidade de baterias) que emitem resposta a sinais de radiofreqüência e que funcionam com um código criptografado que permite a liberação do sistema imobilizador e da parte elétrica do veículo, inclusive o sistema de ignição do motor.

Usando alguns equipamentos leitores comerciais, uma experiência mostrou ser possível burlar o sistema e obter informações suficientes para clonar a chave de um veículo. Neste caso específico, a chave-clone permitiu roubar combustível e desativar o alarme, mas não abrir as portas do veículo.

\subsection{Ameaças à privacidade}

A tecnologia RFID pode ser aplicada conforme a necessidade, podendo ser usada para uma série de funções, desde o controle de estoques e identificação de propriedade até a prevenção contra perda ou roubo. Todas as possibilidades de uso levantadas até aqui demonstram o quão mais ágil um processo pode tornar-se com sua utilização.

Quando aplicadas em um ambiente controlado, as etiquetas RFID e os dispositivos leitores funcionam perfeitamente bem. Neste contexto, a maioria das aplicações proporcionadas pela tecnologia é positiva. Contudo, nem todas as aplicações trazem apenas benefícios, também temos o outro lado da moeda.

Por exemplo, uma diferença marcante entre as etiquetas RFID e os tradicionais códigos de barras é que estes são utilizados nos produtos para identificação nas lojas, mas depois da compra perdem a sua função. No entanto, as etiquetas RFID são, em muitos casos, permanentes nos produtos, respondendo sempre que recebem o sinal de um leitor.

A ameaça à privacidade surge quando a etiqueta eletrônica permanece ativa mesmo quando deixa o estabelecimento comercial. Imagine uma residência e tudo o que existe no seu interior, numerado, identificado, catalogado e rastreado com etiquetas eletrônicas. Uma pessoa mal intencionada provida de um leitor poderia, da rua, levantar todos os bens existentes na casa e planejar uma visita sem ser convidado. Neste caso, anonimato e privacidade deixam de existir.

Agora, considere a seguinte situação: uma loja decide colocar etiquetas RFID em todos os produtos a venda. Um cliente faz a compra de vários produtos para sua casa e leva todos com as etiquetas RFID afixadas e ativas. Dias depois, este mesmo cliente retorna à loja portando um dos produtos comprados anteriormente (e ainda com a etiqueta). No momento em que este cliente se aproxima do balcão, a etiqueta automaticamente envia seus dados para os leitores situados no interior da loja, identificando o comprador. Com essa informação um vendedor aborda o cliente oferecendo sugestões baseadas nas suas compras passadas. Este fato caracteriza uma clara perda de privacidade do cliente. 


\subsection{Microchip no dinheiro}

No caso dos microchips colocados nas cédulas de dinheiro, não há duvida de que essa tecnologia traria maior segurança quanto à possibilidade de falsificação, mas também representaria uma mudança radical na forma como nos portamos com nossas finanças.

Considerando que a tecnologia usada dessa forma habilitaria o rastreamento das transações de indivíduo para indivíduo, o dinheiro deixaria de ser uma forma de manter o anonimato nas compras e vendas, além disso, governo e bancos não seriam os únicos a saberem quanto uma pessoa possui ou gasta já que os criminosos também poderiam obter leitores e ter acesso a tais informações de alguma forma.

\subsection{Microchip em documentos}

Uma outra questão, relacionada com a segurança e privacidade das pessoas, diz respeito aos dispositivos RFID na autenticação e uso em documentos importantes como carteiras de motorista, passaportes, diplomas universitários, certidões de nascimento, etc, devido ao risco de roubo de identidade.

As etiquetas RFID para esse tipo de aplicação ainda apresentam um grande inconveniente: não contém nenhuma rotina ou dispositivo extra para proteger seus dados além da criptografia, sendo perfeitamente possível a uma pessoa mal intencionada (e com conhecimento técnico) quebrar o código e roubar a identidade da outra pessoa, em tempo real.

\section{A defesa do consumidor}

O Código de Defesa do Consumidor deve incluir futuramente cláusulas deixando claro que os consumidores devem ser notificados sobre quaisquer produtos colocados a venda contendo etiquetas RFID. Todo consumidor deve saber quando adquire produtos etiquetados desta forma e solicitar a desabilitação dos microchips dos bens adquiridos, se assim desejar.

Por sinal, a União Européia tem demonstrado sua preocupação com a proteção da privacidade e dos direitos humanos no uso da tecnologia de identificação por radiofreqüência. Por meio da Comissão Européia, a entidade criou algumas diretrizes, reunidas em um documento chamado "Article 29 Working Party", que devem ser seguidas por companhias e agências governamentais para proteger os dados e a privacidade das pessoas. Esse documento evidencia a obrigatoriedade da informação e do consentimento dos indivíduos nos locais onde as etiquetas RFID forem utilizadas.

Visando o respeito a privacidade dos consumidores, os estabelecimentos comerciais, financeiros ou de qualquer outro ramo de atividade que envolva o uso de etiquetas RFID deveriam seguir quatro premissas básicas:

Os consumidores devem ser notificados quanto à presença de etiquetas RFID nos produtos e em quais deles isto acontece;

Etiquetas RFID devem ser desativadas após a compra do produto, na saída do estabelecimento, independente de uma solicitação prévia do consumidor;

Etiquetas RFID devem ser colocadas na embalagem do produto e não no próprio produto, visando facilitar sua retirada ou inutilização;

Etiquetas RFID devem estar bem visíveis, devem ser facilmente identificáveis e removíveis pelo cliente. 
Entretanto, mesmo com regulamentação oficial, esta situação de quebra de privacidade pode se tornar corriqueira e rapidamente tornar-se uma das principais ameaças aos direitos dos indivíduos, caracterizando uma nova forma de invasão de privacidade, agora via radiofrequiência, e expondo as pessoas a novos riscos, principalmente quando indivíduos mal intencionados conhecerem melhor e se aproveitarem dos recursos e falhas dessa tecnologia.

\section{Alternativas para proteção}

A RFID e outras tecnologias de identificação wireless levantam questões de privacidade sem antecedentes (GARFINKEL e ROSENBERG, 2005). Felizmente, em meio a tantas possibilidades de violação da segurança, existem estudos e projetos para que a tecnologia RFID seja implantada sem causar danos aos seus usuários. Isso faz com que seu uso em larga escala seja viável e que o cotidiano das pessoas seja facilitado sem maiores transtornos.

Tais soluções não garantem segurança total no uso das etiquetas RFID, porém, já fazem com que esta tecnologia se torne menos vulnerável e mais confiável. São elas:

- Criptografia baseada em chaves: somente emissor e receptor tem acesso ao conteúdo da informação contida na etiqueta. Qualquer pessoa que tente obter esses dados ilicitamente terá que decifrar um padrão criptográfico já comprovadamente testado e confiável;

- Uso de códigos: neste caso, o conteúdo da etiqueta só poderia ser usado mediante o conhecimento de um código adicional. Por exemplo: em um supermercado, o usuário deveria usar um código pessoal no caixa para liberar a compra usando um Smart Card dotado de um microchip RFID;

Blindagem metálica: Como a tecnologia lida com campos eletromagnéticos, é natural que metais interfiram no seu desempenho. Encapsulamentos especiais podem contornar esta limitação, possibilitando que produtos de grande volume como peças industriais, automóveis, containeres, etc, possam utilizar um microchip. Outra alternativa é acondicionar produtos menores em embalagens com material reflexivo (alumínio, por exemplo), para que estes fiquem livres de interceptações indevidas quando não estiverem a venda ou em uso.

\section{Desafios da tecnologia}

Embora tenham ocorrido avanços consideráveis com a tecnologia RFID, diversos desafios ainda se mostram reais para sua ampla utilização. Esses desafios se concentram na aplicação que é feita dos dispositivos, sendo que para determinadas aplicações, a tecnologia está razoavelmente consolidada, enquanto que para outras ainda deve aguardar o desenvolvimento de novos dispositivos e protocolos de segurança.

Dentro dessa realidade, podemos considerar que os principais desafios a serem enfrentados pela tecnologia são:

Custos: embora os preços dos sistemas RFID estejam bem mais competitivos em relação aos sistemas por códigos de barras, para produtos de baixo valor agregado esta substituição não se mostra ainda tão vantajosa. Atualmente o custo da etiqueta não é o maior problema, o investimento mais pesado ainda está na integração dos sistemas; 
Fontes de energia: para dispositivos RFID ativos o tempo de duração das baterias ainda é um problema. A curta duração da carga das baterias atuais limita o desenvolvimento de novos dispositivos e aplicações que requerem mais poder de processamento, que por sua vez requerem maior fornecimento de energia. Para dispositivos passivos, embora estes sejam energizados apenas no momento da utilização, a energia obtida é inversamente proporcional à distância entre eles e o leitor, ou seja, quanto maior a distância, menor a energia para o microchip. Isto também limita o desenvolvimento de novas aplicações, obrigando que as etiquetas fiquem mais próximas do leitor para processamento, o que pode fugir ao propósito da aplicação;

Distância do leitor: algumas aplicações podem requerer que a identificação seja feita em distâncias ainda não atendidas pelos dispositivos leitores atuais. A leitura também pode ser dificultada em ambientes com muitos obstáculos, principalmente aqueles com objetos metálicos de grande volume;

Miniaturização: algumas aplicações podem necessitar de dispositivos imperceptíveis à visão e ao tato para permitir sua total integração à rotina das pessoas. Outras podem requerer uma alta concentração de dispositivos em um mesmo local, de modo que o tamanho atual dos microchips poderia inviabilizar uma aplicação em especial;

Superfícies metálicas: Restrições de uso em ambientes sujeitos a interferência eletromagnética e materiais metálicos ou condutivos, que dificultam a transmissão dos sinais de radiofreqüência entre o Transponder e o Leitor RFID;

Normas e padrões: Regulamentação ao nível nacional e internacional ainda não compatíveis e falta de processos que agilizem a inserção do microchip conforme o tipo de produto.

\section{RFID e as pragas digitais}

Sistemas RFID podem ser bastante atrativos para usos mal intencionados, uma vez que os dados gravados nas etiquetas podem conter informações estratégicas. Além de causar danos aos sistemas eletrônicos, bancos de dados, etc, as pragas digitais para RFID podem também causar efeitos danosos em objetos e até mesmo em pessoas.

Estudos realizados recentemente na Faculdade de Ciências da Universidade Livre de Amsterdam, na Holanda, por uma equipe chefiada pelo professor americano Andrew C. Tanenbaum comprovaram que é possível um vírus se auto-replicar por meio de etiquetas RFID.

Segundo Tanenbaum (2006):

Devido a algumas vulnerabilidades presentes nos atuais sistemas leitores, uma etiqueta infectada poderia transmitir um vírus para o banco de dados utilizado por um programa de controle de estoques, por exemplo. Por sua vez, esse vírus poderia ser retransmitido para outras etiquetas RFID e para toda a rede. Até mesmo os animais de estimação com etiquetas de identificação implantadas sob a pele poderiam ser um veículo para a disseminação desse tipo de vírus.

Apesar de nenhuma praga digital para RFID ter sido descoberta ainda, de acordo com os resultados desse mesmo estudo, um vírus pode aproveitar as mesmas falhas que os programas espiões e os outros vírus exploram nos PC's e nas redes de computadores. As etiquetas eletrônicas apresentam diversas características que podem ser empregadas para explorar vulnerabilidades no middleware e em bancos de dados. Os ataques podem acontecer na forma de uma invasão por SQL ou um ataque de estouro de memória mesmo que as etiquetas tenham pouca memória e armazenem pouca informação, conclui o estudo. 


\section{O futuro da tecnologia}

Podemos concluir que a tecnologia de Identificação por Radiofreqüência está sendo cada vez mais utilizada em conjunto com outros sistemas de identificação automática nos setores onde há necessidade de monitoração, rastreamento e coleta de dados. Atualmente, as principais áreas de aplicação da RFID são transporte e logística, indústria, comércio e segurança.

Entretanto, é preciso lembrar sempre que os microchips são dispositivos limitados, ou seja, eles "ouvem" e "respondem" a solicitações que são enviadas, mas não distinguem as fontes dos sinais. Qualquer sinal que um leitor RFID obtém de um Transponder pode ser igualmente captado por outros dispositivos similares e este acesso não autorizado às informações poderá vir a se constituir em ameaça a segurança de qualquer indivíduo ou organização.

Apesar de ainda existirem restrições para uma maior utilização da tecnologia RFID, que variam desde a concepção do projeto, falta de padrões e custos elevados, até a dificuldade da análise dos dados coletados, é certo que todos os profissionais envolvidos com sua aplicação precisam se conscientizar que utilizar a tecnologia com segurança é uma questão fundamental.

\section{Referências bibliográficas}

FINKENZELLER,Klaus. RFID Handbook: Fundamentals and Applications in Contactless Smart Cards and Identification. 2 ed. New York: John Wiley \& Sons, Ltd., 2003.

GARFINKEL, Simson, ROSENBERG, Beth. RFID: Applications, Security, and Privacy. 1 ed. New York: Addison Wesley, 2005.

RIEBACK, Melanie, CRISPO, Bruno, TANENBAUM Andrew C. Is your cat infected with a computer virus? In Pervasive Computing and Communications. Pisa, Itália: IEEE, IEEE Computer Society Press., 2006.

PINHEIRO, José Maurício S. Identificação por Radiofreqüiência. Revista PC's Redes e Internet, vol 2, no 17, pág 61-66, São Paulo, 2004.

\section{Informações bibliográficas:}

Conforme a NBR 6023:2002 da Associação Brasileira de Normas Técnicas (ABNT), este texto científico publicado em periódico eletrônico deve ser citado da seguinte forma:

PINHEIRO, J. M. S.. Identificação por Radiofrequiência: Aplicações e Vulnerabilidades da Tecnologia RFID. Cadernos UniFOA, Volta Redonda, ano 1, n. 2, nov. 2006. Disponível em: <http://www.unifoa.edu.br/pesquisa/caderno/edicao/02/18.pdf> 